\title{
Investigative practice into sudden death in epilepsy: A global survey
}

\section{Michael O Kinney ${ }^{1}$, Gavin McCluskey ${ }^{1}$, Daniel Friedman², Matthew C Walker ${ }^{3}$, Josemir W Sander ${ }^{3,4,5}$, Rohit Shankar ${ }^{6,7}$}

1. Department of Neurology, The Royal Victoria Hospital, Belfast Heath and Social Care Trust, BT9 $7 A B, U K$.

2. NYU Comprehensive Epilepsy Centre, Langone Medical Health, New York, NY 10016, USA.

3. UCL Institute of Neurology, Queen Square, London, WC1N 3BG UK.

4. Chalfont Centre for Epilepsy, Buckinghamshire SL9 0RJ, UK

5. Stichting Epilepsie Instellingen Nederland (SEIN), Achterweg 5, 2103 SW Heemstede, Netherlands

6. Department of Intellectual Disability Neuropsychiatry, Cornwall Partnership NHS Foundation Trust, Truro, TR1 3QB UK.

7. Exeter Medical School, Knowledge Spa, Truro, TR1 3HD UK.

\section{Corresponding author's contact information}

Dr. Rohit Shankar MBE, FRCPsych

Department of Developmental Neuropsychiatry

Chygovenck, Threemilestone industrial estate Truro TR4 9LD

Phone: +44-01872221553

Fax: +44-1872 240765

Email: Rohit.shankar@nhs.net

Word count excluding title page, abstract and references: 2382 words

References: 35

Tables -3

Supplementary information (for online) - 3

Running title - Global survey of attitudes to sudden death

Keywords: Epilepsy; treatment gap; global health; SUDEP; sudden death; epilepsy mortality

\section{Conflict of interest-}

MOK received salary support for an out of programme sabbatical from UCB paid through the Belfast Health and Social Care Trust outside the submitted work.

GMcC has no conflicts of interest

DF serves on the North American SUDEP Registry executive committee. He receives salary support from the non-profit Epilepsy Study Consortium. He has consulted or serves on advisory boards for Eisai, GW Pharmaceuticals, LivaNova, Penumbra, Supernus, and UCB. He has received an honorarium for educational materials from Neuropace. He receives research support from NINDS, Epilepsy Foundation, the Centers for Disease Control and Prevention, and UCB Pharmaceuticals for work unrelated to this study.

MCW has received departmental research support from Vitaflo and has been consulted by and received fees for lectures from GSK, Pfizer, Eisai and UCB outside the submitted work. 
JWS has received departmental research support from Eisai and UCB Pharma and has been consulted by and received fees for lectures from Bial, Eisai, Janssen and UCB Pharma outside the submitted work.

RS is a principal stakeholder of the 'SUDEP and Seizure Safety Checklist', a developer of EpSMon and on the advisory committee of the UK epilepsy death register. RS has received institutional and research support and personal fees from LivaNova, UCB, Eisai, Veriton Pharma, Bial and Desitin outside the submitted work.

\section{Acknowledgements:}

Prof. Chris Patterson, Centre for Public Health, Queen's University Belfast, Northern Ireland, for statistical advice. MCW and JWS are based at NIHR University College London Hospitals Comprehensive Research Centre, which receives a proportion of funding from the UK Department of Health's Biomedical Research Centre's funding scheme. JWS receives research support from the Dr. Marvin Weil Epilepsy Research Fund and his current position is endowed by Epilepsy Society, UK.

\section{Funding:}

No specific funding was obtained for this study.

\section{Data Availability:}

Data availability requests can be directed to the corresponding author and made available as required in appropriate situations. 


\section{Abstract}

Objectives: Sudden death is a recognised consequence of epilepsy. Little is known about the practice of confirming the cause of sudden death from most nations. We sought to determine how often autopsy is undertaken, clinician confidence in cause of death, and identify the factors which may influence autopsy utilization.

Materials \& Methods: An online questionnaire survey was sent to all International League Against Epilepsy (ILAE) chapters chairpersons, asking them to complete the survey based on their perceptions in their country. Questions included: confidence in cause of death in people with epilepsy, frequency of autopsy uptake, and perceived barriers to an accurate diagnosis and ongoing research work. Data was analysed by chi squared, Kruskal-Wallis and Spearman rank analysis.

Results: Responses were obtained from 77 of 114 individual chapter leaders (68\%). Legal, coronial, family attitudes, including cultural and religious factors, to autopsy were considered the major barriers to obtaining an accurate diagnosis. Only $13 \%$ had a high level of confidence in the accuracy of the cause of death. There was greater confidence in the diagnosis of the causes of sudden death in epilepsy in the countries with higher autopsy rates. Sixty-six percent of responders were not aware of published or unpublished research or audits on sudden death in epilepsy in their country in the last decade.

Conclusions: Significant disparities exist in the investigation of sudden death in epilepsy across countries and identified factors in this study provide an opportunity to formulate a global public health strategy to help overcome this gap. 


\section{Introduction}

Globally there are over 50 million people with epilepsy, of whom $80 \%$ live in middle or low income countries, where there is a large diagnostic and treatment gap resulting in sub-optimal care and often no effective epilepsy care ${ }^{1-5}$.

People with epilepsy have an increased risk of premature mortality ${ }^{6}$ due to various factors; accidental deaths including drowning, status epilepticus, suicide and sudden unexpected death in epilepsy (SUDEP). Standardized mortality ratios (SMR) for epilepsy are lower in high income countries in comparison to low income nations ${ }^{7,8}$. A definite diagnosis of SUDEP9 ${ }^{9}$ can be made when a person with epilepsy dies suddenly, and unexpectedly, typically in benign circumstances when no toxicological cause, alternative medical cause, or a structural anatomical cause is identified at autopsy as being the more like cause of death. Alternative designations can include probable SUDEP and possible SUDEP in situations where an autopsy is not performed. One critical factor in determining a diagnosis of SUDEP and its incidence is therefore the rate of autopsy.

Studies in largely high income nations have identified SUDEP as a leading cause of premature mortality in people with chronic epilepsy ${ }^{10}$. Incidence studies in low and middle income settings are lacking ${ }^{7}$. The substantial under-ascertainment of SUDEP deaths in high income countries ${ }^{11,12}$ is magnified in low income countries in which there are limited resources for a post-mortem investigation precluding reliable assessment of cause of death ${ }^{13}$.

Of the other causes of epilepsy-related mortality, status epilepticus has been recognized to have a higher case fatality rate in low and middle income countries ${ }^{7}$ due to lack of availability of intensive care facilities and less robust prehospital care ${ }^{14}$. Low income settings have also higher risks of premature mortality due to accidental deaths and suicide ${ }^{7}$. The spectrum of aetiology of epilepsy also differs with low-moderate income countries (LMIC) having a higher risk of certain acute symptomatic causes which could also be fatal in their own right, such as cerebral malaria, TB, and HIV.

Despite the fact that low and middle income countries are disproportionately affected by epilepsy ${ }^{15}$ and its consequent elevated risk of mortality ${ }^{7,8}$ little is currently known about the practice of investigating sudden death is in these countries, and how this might be affected by local cultural practices.

We attempted to determine the confidence clinicians have in the reported cause of SUDEP in different countries. Additionally we wanted to determine the extent of post-mortem examination in cases of suspected SUDEP and to assess the role of certain factors influencing the pursuit of a post-mortem diagnosis. 


\section{Methods}

A short online survey in English delivered via a web based survey provider was developed and the questionnaire approved by an expert focus group (supplementary information 1). A formal validation was not carried out in this pilot study. It was disseminated by an email link with an invitation to complete the survey. Four remainder emails were sent out in total at monthly intervals. Reminders were not resent to those who had replied.

The International League against Epilepsy (ILAE) provides a unique structure of epilepsy specialists in 114 countries, with specialists in local leadership roles due to local prominence and advocacy roles within the epilepsy community. It was sent in October 2017 to all national chapter chairpersons of the ILAE (supplementary information 2), and was kept open for 4 months. If unavailable, or if the email wasn't delivered, it was redirected to the chapter vice-chairperson. In 2 cases another nominated expert was suggested who was approached to provide a more representative answer.

No ethical permission was required as this was a survey to evaluate attitudes. Consent was implicit by returning the survey. Participation was voluntary and replies were anonymized and analyzed. The NHS health research tool determined no ethics review were needed (supplementary information 3).

The countries were stratified by economic development, religious majority, and ILAE regional commission status, which is broadly consistent with continental geography. Economic development was based on the 2014 per capita gross national income (GNI), as per the World Bank Atlas method ${ }^{16}$. Countries were subdivided into three main categories; low-income countries $(<\$ 4126)$, middle-income countries $(\$ 4126$ $\$ 12,735$ ) and high-income countries (\$12736 or higher). The regional commission in which countries are located was obtained from the ILAE ${ }^{17}$. For the determination of religious majority, figures were obtained from Wikipedia and an arbitrary figure of $70 \%$ was used to define a majority ${ }^{18}$.

Statistical analysis was performed using SPSS version.23.0 (IBM Corp., Armonk NY). For tests of significance; Chi-squared analyses was used as well as the Kruskal-Wallis (KW) test to compare ordinal response questionnaire data between groups. Spearman's Rank Correlation Coefficient was used to determine the relationship between clinician confidence in diagnosis and likelihood to perform autopsy, following this $\mathrm{KW}$ test was used to assess statistical significance between groups, based on economic status, commission grouping, and religion.

\section{Results}

Eighty-one replies from individual countries were received of which four were excluded due to duplicate entries, leaving 77 eligible responses a response rate of $68 \%$ [Table 1]. Table 2 provides country characteristics for responders. There were no identified statistical differences between the groups of responders and non-responders (Table 2). Official English language status of the country did not predict response to the questionnaire $(p=0.29)$. 
The responses from the survey are shown in Figure 1. These results show that post-mortem was rarely carried out in cases of sudden death; $56 \%$ of responders stating that an autopsy was only carried out between an estimated $0-19 \%$ of the time, and only $21 \%$ reported that it was nearly always or always carried out (between $80-100 \%$ of cases). In scenarios where autopsy was not carried out in $100 \%$ of cases, the most frequent reasons cited for it not having been carried out were family wishes and cultural considerations. Several "other" answers were volunteered in free text comments (Supplementary information 4a).

When asked who had the final decision on whether to perform an autopsy in sudden death in epilepsy, $57 \%$ reported it was the coroner, and a family decision in $18 \%$. In the remainder, it was the neurologist or pathology department who made the decision regarding investigation of the death. Ten percent stated "other" and went on to state that medico-legal representatives, forensic medicine specialists, the public prosecutor, or the individual's physician or local physician dealing with the death may determine the need for autopsy. Few respondents (18\%) were aware of research or audit being carried out in their country over the last decade in this area. The biggest barrier to successfully identifying the cause of death was perceived to be family wishes (47\%) followed by legal processes (30\%). Several free text replies were volunteered which identified various barriers (Supplementary file $\mathbf{4 b}$ ).

Overall confidence in the diagnosis of an accurate cause of death was found with a high level of confidence in $13 \%$ of cases, moderate in $42 \%$, low in $31 \%$ and no confidence in $14 \%$. To determine how necessary clinicians found autopsy to be in cases of sudden death in epilepsy, confidence in diagnosis was correlated with the frequency with which autopsy was performed. These data are shown in Figure 2 . This shows that countries which reported moderate and high confidence in diagnosis reported that autopsy was carried out on a more frequent basis [Spearman's rho 0.438 ( 2 tailed $p$ value $<0.001)$ ].To determine which factors might be having an impact on autopsy being performed, the groups were analyzed per economic status, commission grouping, and religious majority. Each of these three variables significantly impacted on autopsy frequency (See table 3). Countries with high income status, of European origin, and with Christian religious majority predicted increased frequency of autopsy. Further analysis was carried out to determine what if any factors might identify the "biggest barriers" to successful cause of death identification. World Bank status $(p=0.34)$, religion $(p=0.06)$ were not significant yet regional commission did have a significant influence $(P=0.007)$ [Chi ${ }^{2} 38.617$, df 20]. Figure 3 assesses this further, and shows the spectrum of barriers across the different geographical locations, with legal factors being more at play in at least $50 \%$ in North America and Europe, and family factors being relevant across all locations, but to a greater extent in in Africa, Asia and Oceania, and Eastern Mediterranean. Access to pathology was an issue in approximately $20 \%$ of cases in Eastern Mediterranean, Latin America, and African regions. The amount of research carried out was also considered from the perspective of the different characteristics. In high income countries, $37 \%$ respondents identified research/audit in the last decade in their country, in comparison to only $9 \%$ in low income and $6 \%$ of middle income countries (Chi ${ }^{2} 12.56$, degrees of freedom (df) 4,2 sided $p=0.01$ ). Research was not correlated with religion (P 0.06), or commission location ( $p$ 0.92). 


\section{Discussion}

A major finding is the identification of a gap in the robust investigation into sudden death in people with epilepsy and consequent low confidence in the identified cause of sudden death in epilepsy diagnosis. The impact of economic factors, geographical location, and religion has been identified as possible aspects contributing to low uptake of autopsy. The majority of surveyed nations do not appear to participate in active audit or research into epilepsy mortality, which is consistent with the published research volume from the different participant countries.

In low-income countries the identification of an accurate cause of death is challenging, due to limitations of various resources. This is consistent with other similar findings of high quality data about cause of death lacking from $65 \%$ of the world population ${ }^{19}$.

Access to pathologists to carry out post-mortems was an issue in several regions, which limits the ability to provide a gold standard assessment. In 2006 in the UK, The Royal College of Pathologists issued guidelines on best practice in investigation of SUDEP, recommending a neuropathological assessment to include a whole brain examination. The utility of this approach has been demonstrated in the $\mathrm{UK}^{20}$ where neuropathological findings were identified in $89 \%$ of SUDEP cases examined. This highlights the importance of expert neuropathological assessment in these challenging cases, recently reiterated by the US National Association of Medical Examiners ${ }^{21}$. "Access to pathology was not considered to be a main barrier in Asian and Oceania to the identification of the cause of death. This could be for several reasons, namely established well developed pathology services in some countries, however in a general way it is more likely that other factors out-weigh concerns regarding pathological assessment given the treatment gap that exists in many Asian countries ${ }^{22}$. In Europe and North America, the legal system was more likely to be a barrier, this likely refers to the coronial processes in investigation of sudden death. This is likely a reflection of the suggestion that some coronial/forensic pathologists are reluctant to use the term SUDEP on death certification ${ }^{23}$.

Pragmatic solutions, validated for SUDEP, which are suited to the limited resources of low and middle income countries are needed to identify cause of death, when post-mortem is not available. One solution is the WHO verbal autopsy, which is a structured interview of decedents relatives to ascertain events leading up to the death, to determine aetiology ${ }^{24,25}$. A further solution is the minimally invasive autopsy, where tissue biopsy and bodily fluids are extracted for examination. In a study of Asian and African countries ${ }^{26} 75 \%$ of showed an openness to use this approach.

This includes needing solutions for when religious beliefs preclude autopsy, such as in Judaism and Islam which have deeply held views regarding the importance of maintaining bodily integrity, considered violated by autopsy, and a need to pursuing a rapid burial. Both faiths have permitted exceptions ${ }^{27,28,29}$. Alternative options include genetic assessments ${ }^{30}$, or post-mortem imaging based autopsy ${ }^{31}$. Whilst not validated for SUDEP these techniques may offer potential to exclude competing causes of death.

Our survey identified several countries with low confidence in the cause of death being identified despite a high autopsy rate, perhaps reflecting under-recognition of SUDEP among coroner and medical examiner 
offices $^{12}$. Other studies have shown that contributions from seizures or epilepsy are infrequently recorded at death certification ${ }^{32}$, with particular neglect to the SUDEP Plus category ${ }^{33}$.

Areas where low autopsy rates with high confidence were reported likely reflects clinician overconfidence, but could also indicate some clinicians considered the "apparently evident" causes of death such as downing or trauma in this question This highlights the importance of the need for ongoing educational initiatives ${ }^{21,34,35}$.

\section{Limitations and strengths}

The strengths are the large scale international perspective, with a relatively high response rate across a group of highly informed individuals on the subject matter inquired.

In terms of limitations, certain subgroup analysis is limited by small numbers resulting in certain elements being under-powered to detect subtle differences, for example differences in certain religious groups. The study was an exploratory pilot study, and by this nature would not have had statistical power to detect small group differences, and this must be considered in interpreting the results. The use of a $70 \%$ majority related to the religious majority was an arbitrary figure, due to the inherent complexities of determining religious sentiment even in states which have an official religion.

A further limitation is that we only considered location, religion, and economic development; other factors confounders, such as the type of health service could have influenced results. Surveys' were only sent in English, which may have resulted in limited uptake, among some countries. Most if not all ILAE leadership is likely to be familiar with English, but it could have resulted in some potential bias in replies.

To maximize uptake and reduce "survey fatigue", the survey was short, and did not seek detailed information regarding participant background, such as adult or pediatric practice, or years of practice. This was felt appropriate for a pilot study of this nature, which sought a reply from experts in epilepsy in positions of local prominence in the epilepsy community. Only one opinion was sought for each country, which may offer a limited insight, and limit generalizability. Further work, would assess multiple clinicians perspectives to reduce subjective experience of individual clinicians, including forensic pathologists, neuropathologists, and epilepsy specialists. Further work would also require validation procedures in the questionnaire implementation phase, and could be based on the experience contained here.

\section{Conclusion}

This study has highlighted that clinician confidence in determining accurate cause of death is influenced by the rate of autopsy and the country of practice. 


\section{References}

(1) Meinardi H, Scott RA, Reis R et al; ILAE Commission on the Developing World. The treatment gap in epilepsy: the current situation and ways forward. Epilepsia 2001;42:136-49

(2) Ngugi AK, Bottomley C, Kleinschmidt I et al. Estimation of the burden of active and life-time epilepsy: a meta-analytic approach. Epilepsia 2010;51:883-90

(3) Ngugi AK, Kariuki SM, Bottomley C et al. Incidence of epilepsy: a systematic review and metaanalysis. Neurology 2011;77:1005-12

(4) Scott RA, Lhatoo SD, Sander JW. The treatment of epilepsy in developing countries: where do we go from here? Bull World Health Organ. 2001;79:344-351

(5) Meyer AC, Dua T, Ma J et al. Global disparities in the epilepsy treatment gap: a systematic review. Bull World Health Organ. 2010;88:260-6

(6) Hitiris N, Mohanraj R, Norrie J et al. Mortality in epilepsy. Epilepsy Behav. 2007;10:363-76

(7) Levira F, Thurman DJ, Sander JW, et al. Premature mortality of epilepsy in low- and middle-income countries: A systematic review from the Mortality Task Force of the International League Against Epilepsy. Epilepsia 2017;58:6-16

(8) Thurman DJ, Logroscino G, Beghi E, et al. The burden of premature mortality of epilepsy in highincome countries: A systematic review from the Mortality Task Force of the International League Against Epilepsy. Epilepsia 2017;58:17-26

(9) Nashef L, So E, Ryvlin P, et al. Unifying the definitions of sudden unexpected death in epilepsy. Epilepsia 2012;53:227-33

(10)Devinsky O, Hesdorffer DC, Thurman DJ et al. Sudden unexpected death in epilepsy: epidemiology, mechanisms, and prevention. Lancet Neurol. 2016;15:1075-88

(11)Sveinsson O, Andersson T, Carlsson S et al. The incidence of SUDEP: A nationwide populationbased cohort study. Neurology 2017;89:170-177

(12)Devinsky O, Friedman D, Cheng JY et al. Underestimation of sudden deaths among patients with seizures and epilepsy. Neurology 2017;89:886-892

(13) Ge Y, Ding D, Zhang Q, et al. Incidence of sudden unexpected death in epilepsy in communitybased cohort in China. Epilepsy Behav. 2017;76:76-83

(14)Lee B; Asian Status Epilepticus Survey Group.Treatment gap for convulsive status epilepticus in resource-poor countries. Epilepsia. 2018;00:1-5.

(15)Newton CR, Garcia HH. Epilepsy in poor regions of the world. Lancet. 2012;380:1193-1201

(16)World Bank Group. World Development Indicators. Available from https://openknowledge.worldbank.org Accessed 24 Jan 2017

(17)International League against Epilepsy. Available from https://www.ilae.org. Accessed 29 May 2018

(18)Wikipedia. Available from https://en.wikipedia.org/wiki/Religions_by_country accessed $15^{\text {th }}$ May 2018

(19)WHO. World Health statistics 2013, Geneva, Switzerland: World Health Organization; 2013 
(20)Thom M, Michalak Z, Wright G et al. Audit of practice in sudden unexpected death in epilepsy (SUDEP) post mortems and neuropathological findings. Neuropathology and Applied Neurobiology 2016;42:463-476

(21)Middleton O, Atherton D, Bundock E, et al. National Association of Medical Examiners position paper: Recommendations for the investigation and certification of deaths in people with epilepsy. Epilepsia. 2018;59:530-543

(22)Trinka E, Kwan P, Lee B, Dash A. Epilepsy in Asia: Disease burden, management barriers, and challenges. Epilepsia 2018 Jun 28. doi: 10.1111/epi.14458. [Epub ahead of print]

(23)Zhou L, Zhang Y, Zielke HR, et al. Sudden unexpected death in epilepsy: Evaluation of forensic autopsy cases. Forensic Sci Int 2012;223(1-3):171-5

(24)Nichols EK, Byass P, Chandramohan D et al. The WHO 2016 verbal autopsy instrument: An international standard suitable for automated analysis by interVA, InSilicoVA, and Tariff 2.0. PLoS Med 2018;15::e1002486

(25)Lathers CM, Schraeder PL. Verbal autopsy and SUDEP. Epilepsy Behav 2009;14:573-6

(26)Maixenchs M, Anselmo R, Zielinski-Gutiérrez E et al. Willingness to Know the Cause of Death and Hypothetical Acceptability of the Minimally Invasive Autopsy in Six Diverse African and Asian Settings: A Mixed Methods Socio-Behavioural Study. PLoS Med. 2016;13::e1002172.

(27)Chakraborty R, El-Jawahri AR, Litzow MR et al. A systematic review of religious beliefs about major end-of-life issues in the five major world religions. Palliative and Supportive Care 2017;15:609-622

(28)Sajid MI. Autopsy in Islam: Considerations for Deceased Muslims and Their Families Currently and in the Future. Am J Forensic Med Pathol. 2016;37:29-31

(29)Goodman NR, Goodman JL, Hofman WI. Autopsy: Traditional Jewish laws and customs "Halacha". Am J Forensic Med Pathol. 2011;32:300-3.

(30)Michaud K, Mangin P, Elger BS. Genetic analysis of sudden cardiac death victims: a survey of current forensic autopsy practices. Int J Legal Med. 2011;125:359-66.

(31)Ben Taher M, Pearson J, Cohen $\mathrm{M}$ et al. Acceptability of post-mortem imaging among Muslim and non-Muslim communities. Br J Radiol. 2018;14:20180295.

(32)Schraeder PL, Delin K, McClelland RL et al Coroner and medical examiner documentation of sudden unexplained deaths in epilepsy. Epilepsy Res 2006;68:137-143.

(33)Atherton DS, Devinski O, Hesdorffer DC, et al. Implications of death certification on sudden death in epilepsy (SUDEP) research. Acad Forensic Pathol 2016;6:96-102

(34)Harden C, Tomson T, Gloss D, et al. Practice guideline summary: Sudden unexpected death in epilepsy incidence rates and risk factors: report of the Guideline Development, Dissemination and Implementation Subcommittee of the American Academy of Neurology and the American Epilepsy Society. Neurology. 2017;88:1674-1680

(35)Shankar R, Donner EJ, McLean B et al. Sudden unexpected death in epilepsy (SUDEP): what every neurologist should know. Epileptic Disord. 2017;19:1-9 
Table 1. Countries which responded classified according to the World Bank Gross national Income

*Taiwan is not a member of the World Bank, but is considered a high-income country and has been included in this category for the study purposes.

\begin{tabular}{|c|c|c|}
\hline Low Income & Middle Income & High Income \\
\hline $\begin{array}{l}\text { Cote d'Ivoire, Democratic Republic } \\
\text { of Congo, Ghana, Kyrgyz Republic, } \\
\text { Mali, Myanmar, Pakistan, Rwanda, } \\
\text { Tanzania, Uganda, Zimbabwe }\end{array}$ & $\begin{array}{l}\text { Albania, Argentina, Brazil, Bulgaria, } \\
\text { Costa Rica, Colombia, Croatia, } \\
\text { Cuba, Dominican republic, } \\
\text { Ecuador, Honduras, Hungary, } \\
\text { Indonesia, Iraq, Latvia, Lithuania, } \\
\text { Macedonia FYR., Malaysia, } \\
\text { Mexico, Moldova, Montenegro, } \\
\text { Morocco, Nicaragua, Nigeria, } \\
\text { Panama, Paraguay, Peru, } \\
\text { Philippines, Poland, Romania, } \\
\text { Slovak Republic, Syrian Arab Rep., } \\
\text { Thailand, Tunisia, Turkey, Ukraine. }\end{array}$ & $\begin{array}{l}\text { Australia, Austria, Barbados, } \\
\text { Canada, Cyprus, Czech Republic, } \\
\text { Denmark, Finland, France, } \\
\text { Germany, Greece, Ireland, Israel, } \\
\text { Italy, Japan, Korea Rep., Kuwait, } \\
\text { Malta, Netherlands, New Zealand, } \\
\text { Norway, Portugal, Qatar, Saudi } \\
\text { Arabia, Singapore, Sweden, } \\
\text { Switzerland, Taiwan*, United Arab } \\
\text { Emirates, United Kingdom }\end{array}$ \\
\hline
\end{tabular}


Table 2: The characteristics of the responders to the survey

\begin{tabular}{|c|c|c|c|}
\hline Category & Sub-category & $\begin{array}{c}\text { Responders/ } \\
\text { Total group } \\
(\%)\end{array}$ & $\begin{array}{l}\text { Chi }^{2} \\
\text { Level of significance } \\
\text { ( } p \text { value) [difference } \\
\text { between responders } \\
\text { and non-responders] }\end{array}$ \\
\hline \multirow[t]{4}{*}{ Economic situation: } & Low income & $\begin{array}{ll}11 / 16 \quad(69) \\
\end{array}$ & \multirow[t]{4}{*}{$p=0.26$} \\
\hline & Middle income & $36 / 59 \quad(61)$ & \\
\hline & High income & $30 / 39 \quad(77)$ & \\
\hline & Total & $77 / 114(68)$ & \\
\hline \multirow[t]{6}{*}{ Regional commission } & African & $9 / 14 \quad(64)$ & \multirow[t]{6}{*}{$P=0.97$} \\
\hline & European & $33 / 46 \quad(72)$ & \\
\hline & Latin America & $13 / 19 \quad(68)$ & \\
\hline & Asia and Oceania & $12 / 20 \quad(60)$ & \\
\hline & Eastern Med. & $\begin{array}{ll}8 / 12 & (67)\end{array}$ & \\
\hline & North America & (67) & \\
\hline \multirow{3}{*}{$\begin{array}{l}\text { Religious affiliation of the } \\
\text { majority }(70 \%)\end{array}$} & Islam & $14 / 24 \quad(58)$ & \multirow[t]{3}{*}{$P=0.2$} \\
\hline & Christianity & $45 / 60 \quad(75)$ & \\
\hline & $\begin{array}{l}\text { Mixed groups } \\
\text { /other }\end{array}$ & $\begin{array}{ll}18 / 30 \quad(60) \\
\end{array}$ & \\
\hline
\end{tabular}


Table 3: Clinicians estimates of percentage frequency of autopsy being carried out in sudden death cases in epilepsy, in their country per characteristics of economic situation, regional commission, and majority religion.

\begin{tabular}{|c|c|c|c|c|c|c|c|}
\hline \multirow[t]{2}{*}{ Category } & \multirow[t]{2}{*}{ Sub-category } & \multicolumn{5}{|c|}{$\begin{array}{l}\text { Clinicians estimates of } \\
\text { percentage frequency } \\
\text { of autopsy (\%)* }\end{array}$} & \multirow{2}{*}{$\begin{array}{l}\text { Kruskal-Wallis } \\
\text { Level of } \\
\text { significance ( } p \\
\text { value) }\end{array}$} \\
\hline & & \begin{tabular}{l|}
$0-$ \\
19
\end{tabular} & $\begin{array}{l}20- \\
39\end{array}$ & $\begin{array}{l}40- \\
59\end{array}$ & $\begin{array}{l}60- \\
79\end{array}$ & $\begin{array}{l}80- \\
100\end{array}$ & \\
\hline \multirow{3}{*}{$\begin{array}{l}\text { Economic situation: } \\
\text { (Gross national income) }\end{array}$} & Low income & 82 & 0 & 9 & 0 & 9 & \multirow[t]{3}{*}{$P=0.009$} \\
\hline & Middle income & 67 & 6 & 6 & 3 & 19 & \\
\hline & High income & 33 & 7 & 7 & 27 & 26 & \\
\hline \multirow[t]{6}{*}{ Regional commission } & African & 77 & 0 & 11 & 0 & 11 & \multirow[t]{6}{*}{$\mathrm{P}=0.003$} \\
\hline & European & 30 & 9 & 6 & 18 & 36 & \\
\hline & Latin America & 85 & 8 & 0 & 0 & 8 & \\
\hline & Asia and Oceania & 58 & 0 & 17 & 8 & 17 & \\
\hline & Eastern Med. & 88 & 0 & 0 & 12 & 0 & \\
\hline & North America & 50 & 0 & 0 & 50 & 0 & \\
\hline \multirow{3}{*}{$\begin{array}{l}\text { Religious affiliation of } \\
\text { the majority }\end{array}$} & Islam & 86 & 0 & 0 & 14 & 0 & \multirow[t]{3}{*}{$P=0.034$} \\
\hline & Christianity & 51 & 7 & 11 & 31 & 0 & \\
\hline & Mixed/other & 67 & 11 & 11 & 11 & 0 & \\
\hline
\end{tabular}

*Legend: $82 \%$ of clinicians in low income countries estimate that autopsy occurs in $0-19 \%$ of situations where a person with epilepsy dies suddenly. 


\section{Supplementary information 1 Survey questionnaire}

Thank you for participating in our survey. Your feedback is very important.

This will take no more than 2-3 minutes to complete.

By completing this survey we assume your consent to analyse the data and publish the summary findings per region. Individual responses for each country will not be published.

\begin{tabular}{|c|c|}
\hline Survey Question & Survey Answers \\
\hline $\begin{array}{l}\text { When a person with epilepsy dies } \\
\text { suddenly and unexpectedly; how } \\
\text { often is an autopsy performed? }\end{array}$ & \begin{tabular}{|l|} 
Never $(0 \%)$ \\
Rarely (1-19\%) \\
Infrequently (20-39\%) \\
Sometimes (40-59\%) \\
Frequently (60-79\%) \\
Nearly always (80-99\%) \\
Always (100\%) \\
\end{tabular} \\
\hline $\begin{array}{l}\text { If autopsy is not carried out in } 100 \% \\
\text { of cases; What are the reasons for }\end{array}$ & \begin{tabular}{|l|} 
Neuropathology \\
Pathology \\
Family \\
\end{tabular} \\
\hline $\begin{array}{l}\text { this? (Tick the major reasons which } \\
\text { apply) }\end{array}$ & \begin{tabular}{|l|} 
Legal \\
Cultural \\
Neurologist \\
Other \\
\end{tabular} \\
\hline $\begin{array}{l}\text { In your region, who has the final } \\
\text { decision to investigate a sudden } \\
\text { death (in a person with epilepsy) by } \\
\text { autopsy? }\end{array}$ & \begin{tabular}{|l|} 
Coroner \\
Pathology \\
Neuropathology \\
Neurology \\
Cardiology \\
Family \\
Other \\
\end{tabular} \\
\hline $\begin{array}{l}\text { Has audit or research (even } \\
\text { unpublished work) been done on to }\end{array}$ & Yes \\
\hline $\begin{array}{l}\text { quantify the mortality rates in } \\
\text { persons with epilepsy in your country } \\
\text { in the last } 10 \text { years? }\end{array}$ & |No \\
\hline What single factor is the biggest & Lack of access to Neuropathology \\
\hline barrier to the & Lack of access to Pathology \\
\hline $\begin{array}{l}\text { successful identification of cause of } \\
\text { death being identified in the }\end{array}$ & Lack of understanding among Legal/medical examiners \\
\hline $\begin{array}{l}\text { sudden deaths in persons with } \\
\text { epilepsy in your country? }\end{array}$ & \begin{tabular}{|l} 
Lack of family consent for religious/cultural reasons \\
Other
\end{tabular} \\
\hline $\begin{array}{l}\text { What degree of confidence do you } \\
\text { have that the final diagnosis was the }\end{array}$ & \begin{tabular}{|l} 
High \\
Moderate
\end{tabular} \\
\hline correct cause of death? & \begin{tabular}{|l} 
Low \\
None
\end{tabular} \\
\hline
\end{tabular}




\section{Supplementary information 2 ILAE regions and countries}

\begin{tabular}{|c|c|}
\hline North American Chapters & $\begin{array}{l}\text { Canada } \\
\text { Caribbean } \\
\text { USA }\end{array}$ \\
\hline Latin American Chapters & $\begin{array}{l}\text { Argentina } \\
\text { Bolivia } \\
\text { Brazil } \\
\text { Chile } \\
\text { Columbia } \\
\text { Costa Rica } \\
\text { Cuba } \\
\text { Dominican Republic } \\
\text { Ecuador } \\
\text { El Salvador } \\
\text { Guatemala } \\
\text { Honduras } \\
\text { Mexico } \\
\text { Nicaragua } \\
\text { Panama } \\
\text { Paraguay } \\
\text { Peru } \\
\text { Uruguay } \\
\text { Venezuela }\end{array}$ \\
\hline European Chapter & 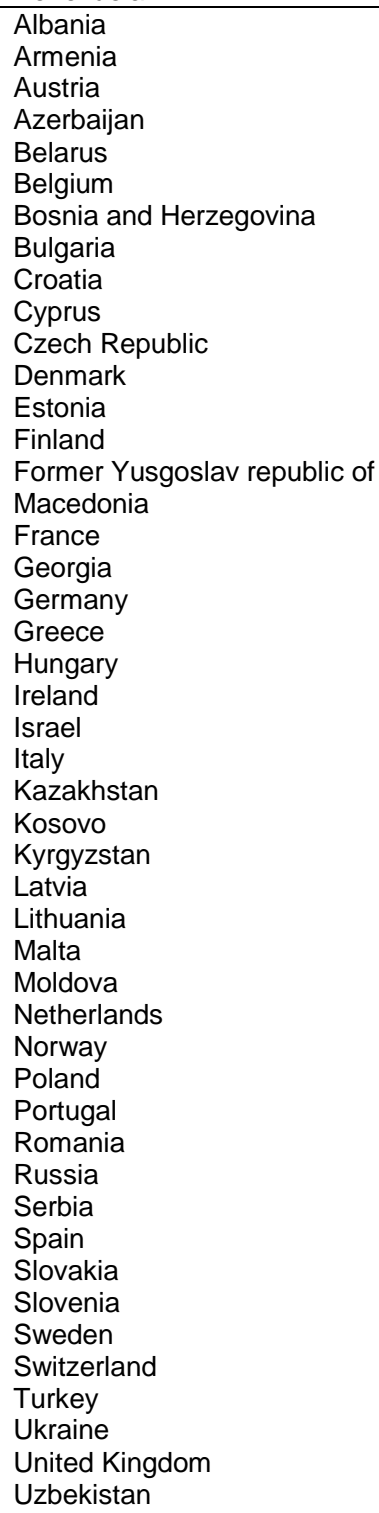 \\
\hline Eastern Mediterranean chapters & $\begin{array}{l}\text { Egypt } \\
\text { Iraq } \\
\text { Jordan }\end{array}$ \\
\hline
\end{tabular}




\begin{tabular}{|l|l|}
\hline & Kuwait \\
& Lebanon \\
Morocco \\
Palestine \\
Qatar \\
Saudi Arabia \\
Syria \\
Tunisia \\
UAE \\
\hline African chapter & Cameroon \\
& Democratic republic of Congo \\
& Ghana \\
& Guinea \\
& Ivory Coast \\
& Kenya \\
& Mali \\
& Nigeria \\
Rwanda \\
Senegal \\
South Africa \\
Tanzania \\
Uganda \\
Zimbabwe \\
\hline Asian and Oceanian Chapter & Australia \\
Bangladesh \\
China \\
Hong Kong \\
India \\
Indonesia \\
Japan \\
Malaysia \\
Mongolia \\
Myanmar \\
Nepal \\
New Zealand \\
Pakistan \\
Philippines \\
Singapore \\
South Korea \\
Sri Lanka \\
Taiwan \\
Thailand \\
Viet Nam \\
\hline \\
\end{tabular}


Supplementary information 3: Confirmation of not requiring formal ethics approval

Go straight to content.

\begin{tabular}{|c|c|c|}
\hline MRC & $\begin{array}{l}\text { Medical } \\
\text { Research } \\
\text { Council }\end{array}$ & $\begin{array}{l}\text { WHS } \\
\text { Health Research Authority }\end{array}$ \\
\hline
\end{tabular}

Is my study research?

i] To print your result with title and IRAS Project ID please enter your details below:

Title of your research:

Investigative practice into sudden death in epilepsy: A global view

IRAS Project ID (if available):

none

You selected:

- 'No' - Are the participants in your study randomised to different groups?

- 'No' - Does your study protocol demand changing

treatment/ patient care from accepted standards for any of the patients involved?

- 'No' - Are your findings going to be generalisable?

Your study would NOT be considered Research by the NHS.

You may still need other approvals.

Researchers requiring further advice (e.g. those not confident with the outcome of this tool) should contact their R\&D office or sponsor in the first instance, or the HRA to discuss your study. If contacting the HRA for advice, do this by sending an outline of the project (maximum one page), summarising its purpose,

methodology, type of participant and planned location as well as a copy of this results page and a summary of the aspects of the decision(s) that you need further advice on to the HRA Queries Line at HRA.Queries@nhs.net.

For more information please visit the Defining Research table.

Follow this link to start again.

Print This Page

NOTE: If using Internet Explorer please use browser print function.

About this tool Feedback Contact Glossary 